\title{
A fuzzy leader-follower game approach to interaction of project client and multiple contractors in time/cost trade-off problem
}

\author{
Ashkan Hafezalkotob ${ }^{a^{*}}$ and Arian Hafezalkotob ${ }^{b}$
}

${ }^{a}$ Department of Industrial Engineering, Islamic Azad University, South Tehran Branch, Tehran, Iran

${ }^{b}$ Department of Mechanical Engineering college, Islamic Azad university, South Tehran Branch, Tehran, Iran

\section{H R O N I C L E}

Article history:

Received: July 5, 2017

Received in revised format: October 10,2017

Accepted: December 5, 2017

Available online:

January 2, 2018

Keywords:

Bi-level distributed programming

problem

Project client

Project contractors

Leader-follower interaction

Game theory

\section{A B S T R A C T}

\begin{abstract}
In recent years, clients often employ multiple contractors to implement different activities of the projects. Each contractor manages and implements a subset of activities according to the determined schedule and payments. In this situation, time/cost trade-off problem becomes a distributed decision making problem in which the client, as leader, and the contractors, as followers, pursue their own objectives. We establish a multi-objective, bi-level distributed programming model based on fuzzy mathematical programming for this time/cost trade-off problem. The model is then developed for three common behaviors of client i.e. profit seeking, minimization of project time, as well as combination of profit seeking and minimization of project time behaviors. As the solution approaches, we propose transformation method based on Karush-KuhnTucker conditions projects to transform bi-level programming problem to a single level one. Numerical results reveal that the client's behaviors have measurable impact on time and cost of activities performed by contractors. Moreover, we found that when the client does not have complete information about the contractors' financial situations, the client should make tradeoff between his confidence level and his profit.
\end{abstract}

\section{Introduction}

Management of large-scale projects can be viewed as management of a bewildering variety of collaborative interactions, agreements, and contracts among independent companies that integrates them as a collaborative network. In the competitive environment of these projects, decreasing time and cost of a project becomes a challenging managerial problem for the clients. Activities of these projects are regularly performed by multiple contractors and these contractors are often independent companies that peruse their own goals. Moreover, the contractors frequently have incentive not to reveal actual information about the cost and the time of the corresponding activities. Therefore, time/cost trade-off problem (TCTP) of a project implemented by multiple contracts turns into a decentralized decision making problem under uncertainty for the client. The project management should be performed based on strategic coordination and cooperation and tradeoffs management rather than conflict management. This * Corresponding author. Tel: +98 9127785681

E-mail address: a_hafez@azad.ac.ir, Hafezalkotob@iust.ac.ir (A. Hafezalkotob) 
paper attempts to present a decision support tool based on fuzzy mathematical programming for the project clients to deal with this complicated problem.

A TCTP is defined as a scheduling and financial plan that creates a balance between the (indirect) marginal value of time saved (in finishing the project one time unit earlier) and the (direct) marginal cost of saving time (Kelley \& Walker, 1959; Kelley, 1961). Therefore, in a TCTP, the activities of the project can be performed more quickly if more resources are allocated to them (Moder et al., 1995). These extra resources can be labor, machinery and or material which also bear additional direct costs for performer. When the value of time saved is very high for the client, time reduction can be regarded as an essential policy. In these situations, the client may provide incentive for contractors (performers) to crash their activities durations by compensating the additional costs. On the other hand, even though the client can presumably estimate the cost and time parameters of contractors, it is unlikely that the contractors would be privy to such information. In this decentralized decision making problem between the client and contractors, the time/cost trade-off plan must then be developed to reflect the objectives and the conflicts-and/or-collaboration between parties.

Leader and followers decision makers roles of client and multi-contractors can be appropriately modelled by bi-level distributed programming problem (BLDPP). A BLDPP is characterized as a hieratical decision making problem in which one decision center at the top level first takes the decision and after that some divisions or decision centers at the bottom level make corresponding decisions based on top level's decision (Lee \& Shih, 2012). The followers at the lower level are supposed independent and under control of the leader at the upper level. Regarding the real system, different kinds of cooperation among the followers can be considered (Lee \& Shih, 2012).

This paper introduces a multi-objective bi-level distributed programming model (MOBLDPP) for TCTP to investigate interaction between one client and multiple independent contractors. Specifically, this research tries to answer the following research questions:

1. With respect to the different policies of a project client, how can TCTP between client and multiple contractors be formulated?

2. What are efficient solution approaches for the small, medium, and large size problems?

3. How do "profit seeking" and "minimization of project duration" policies of client affect total time and cost of the project?

4. How do contractors respond to the "profit seeking" and "minimization of project duration" policies of client?

The reminder of the research is organized as follows. Section 2 reviews the related literature. The prerequisites and assumptions are provided in Section 3, then the formulations of MOBLDPP for TCTP of client and contractors is provided in Section 4. Section 5 gives two solution approaches for the MOBLDPP. Section 5 is devoted to analytical results and sensitivity analysis. Finally, concluding remarks and some directions for future research are summarized in Section 6.

\section{Literature review}

\subsection{Survey on TCTP}

A project is composed of a set of activities being completed over a period of time and aimed to attain particular objectives such as profit, science, or social welfare objectives. TCTP was developed by Kelley and Walker (1959), and Kelley (1961) to schedule the project activities such that a balance between total cost and duration of the project is obtained. They presented a quantitative model for project crashing to specify the suitable activities for compressing (crashing) at minimal costs. The idea of interrelationships among activities formulated by TCTP was then used for development of critical path method 
(CPM) (Moder et al., 1995). Recently, many researchers have focused on the TCTP in project management. Depending the continuous or discrete situation of time/cost relationship of activities, the TCTP can be classified as a discrete time-cost trade-off problem (DTCTP) and continuous time-cost trade-off problem (CTCTP) (Wu et al., 2014). Some researches only concentrated on DTCTP (Hazır et al., 2010; Klanšek \& Pšunder, 2012; Ghoddousi, 2013), or TCTP (Jian-hua \& Wan, 2010); however, Son et al. (2013) considered both DTCTP and CTCTP.

Extra cost and time of the project are especially significant for the project client dealing with multiple contractors. Therefore, project contracts often contain clauses that penalize the contractors if the activities finished later than planned. Furthermore, the client is regularly committed to compensate the extra costs incurred by the contractors to expedite the activities. Thus, in many real industrial projects such as the construction and civil, chemical, and petroleum projects, a TCTP should be developed to incorporate interactions between client and multiple contractors. Jian-hua and Wan (2010) proposed a CTCTP for construction of supply chain by considering one client and one contractor. A bi-level programming problem was developed to simultaneously optimize the revenue of client and contractor when the client uses incentives for the contractor. They only considered total time and cost of total project and time and cost relationship of project's activities were not formulated. Moreover, they did not provide a mathematical solution method for the problem and only investigated the problem with a heuristic algorithm. Hafezalkotob et al. (2017a) established a cooperative game approach for TCTP of multiple contactors of a highway construction case study. Moreover, Hafezalkotob et al. (2017b) developed a game theoretical model for competition and cooperation of a project's contractors when they have interactive activities. They used Shapley value, Core, Max-Min Core, or Equal Profit Method (EPM) methods to distribute the cooperation benefits among contractors in a fair manner.

\subsection{Survey on client and contractors interactions}

In many complex projects, project manager often outsources the activities of the project to contractors. Management of relationship among client and contractors that are often established based on contracts becomes crucially important for successful completion of the project. Our research is also related to project contracting literature.

There are a large number of researches that concentrated on the relationship between client and contractors. Berends (2000) investigated contractual relationship of owner and engineering contractor in oil and chemical industry. He showed that the proposed incentive schemas can present a mechanism to appropriately allocate cost risk to the parties. Rahman and Kumaraswamy (2002) employed rational contracting principles to facilitate joint risk management and reduce transactions costs of all contracting parties. Bubshait (2003) evaluated the perceptions of owners and contractors about incentive/disincentive contracting by questionnaire completed by practitioners of petrochemical plants, power plants, and refineries. Von Branconi and Loch (2004) studied the impact of the contract on the client and many specialized contractors. They suggested eight main levers of the business deal encompassed by the project contract to reach a sound incentive framework for the project. Kadefors (2004) investigated the cooperation and trust effects in project relationships between client and contractor. Lu and Hao (2013) evaluated the effects of trust and power in promoting cooperation between client and contractors. Considering Chines contractors, they found that affect-based-trust has a remarkable positive effect on cooperative performance (rather than cognition-based trust). Vaaland (2004) showed how the relationship based on commitment and trust can reduce continuous challenges between clients and major contractors. Appling Q-methodology in the construction and engineering projects, Suprapto et al. (2015) attempted to reconstruct project practitioner's prospective concerning collaborative relationships between owner and contractors. Xiong et al. (2014) evaluated how the performance of project participants influences contractor project satisfaction. A typical and important issue in contractors and client relationship management is time/cost trade-off between two parties. 


\subsection{Survey on BLDPP}

BLDPP deals with situations in which one leader decision maker cooperates with several follower decision makers. Several actual problems with asymmetric power of parties can be appropriately modelled into BLDPP such as economic duo-ploy systems, government interventions in businesses, and traffic systems, as well as project management with multiple contractors. Cheng (2011) utilized a BLDPP to formulate a sealed-bid, multi-issue, and multi-sourcing reverse auction problem in negotiation between a buyer and a set of suppliers. In the proposed model, the buyer is assumed the leader (i.e., the upper level decision maker) and the suppliers are assumed as independent followers (i.e., lower level decision makers). Mokhlesian and Zegordi (2014) adopted BLDPP to model a multiproduct twostage supply chain composed of one manufacturer and a set of rival retailers. The manufacturer as leader decision maker determines pricing and production value while retailers as followers make purchasing decisions. Similarly, Hafezalkotob and Ghezavati (2015) used BLDPP to formulate distribution network that is composed of one manufacturer and a set of independent distributors. The manufacturer as a leader player considers expected profit, variance of profit and stability level to evaluate distribution network designs. Adopting BLDPP, Yin et al. (2015) established a mathematical model for a supply chain including one manufacturer and multiple suppliers. The proposed model formulated production, price, and inventory decisions under demand uncertainty. Hafezalkotob et al. (2015) formulated government intervention in green and regular supply chains with BLDPP. They assumed that government as Stackelberg leader determines subsidy and tax strategies and then supply chains as Stackelberg followers make the price and marketing decisions.

\subsection{Research gap}

To the best of authors' knowledge, BLDPP has been rarely applied for evaluating TCTP between client and multiple contractors. Our paper is closely related to Yang et al. (2016). They used bi-level programming method to study incentive contract design of project manager for different subcontractors that perform tasks sequentially. However, their problem, decision structure, proposed model, and solution methods are different with those of our research because we consider a network of activities (activity-on-activity (AoA) network) for the project which implemented by multiple contractors. It is notable that in our problem, the contractors are not independent because the activities scheduling of each contractor depend on those of other colleague contractors. We use MOBLDPP to formulate the client payment decisions with contractors' decisions about inter-related activities. We assume that the client may adopt profit seeking or project time minimization policies in the project management. Moreover, we consider incomplete information of the client about time and cost parameters of the contractors. Eventually, exact mathematical solution method (based on transformation approach) is proposed for the problem.

\section{Prerequisites and assumptions}

In the proposed leader-follower game, the contractors as followers of the client decide to maximize their profit of the activities with respect to the activities duration. Therefore, taking account of client payments, contractors should determine the optimal timing for each corresponding activity by choosing a time/cost combination for each activity. The TCTP in the project scheduling works based on CPM formulated on AoA network diagram. Basically, CPM assumes that duration of the project activities is a non-increasing function of the amount of money used to perform that activity (i.e., budget is considered here as a resource). This implies that the cost of an individual activity is a function of its duration, that is, by spending more (or less) budget, duration of the activity duration will decrease (or increase). Moreover, symbols and notations used through the paper are discussed as follows:

$K \quad$ the set of contractors of the project, $K=\{1,2, . ., k, . ., m\}$;

$E \quad$ the set of events (nodes) in the AoA format of project, $E=\{1,2, . ., i, j, . ., n\}$; 
$A$ the set of project activities in the AoA format represented by the acrs in the network, $A=\{(i, j) \mid i, j \in E,(i, j) \equiv \operatorname{arcs}$ of AoA $\}$;

$A_{[k]} \quad$ the set of project activities of contractor $k$ in the AoA format, $A_{[k]} \subseteq A$;

TPP the total project profit for the client;

$\pi \quad$ the value (revenue) of the project for the client;

$T P_{[k]} \quad$ the total profit of contractor $k$ from the corresponding activities;

$T P D$ the total project duration, $\left(T P D=x_{n}\right)$;

$f_{i j[k]}$ the payment from the client to contractor $k$ for activity $(i, j)$;

$e_{i j[k]} \quad$ the reward payment from the client to contractor $k$ for expediting (crashing) activity $(i, j)$ for one time unit;

$y_{i j[k]}$ the expedition (crash) duration of activity $(i, j)$ of contractor $k$;

$N D_{i j[k]}$ the normal (maximum) duration for the activity $(i, j)$;

$C D_{i j[k]}$ the crash (minimum) duration for the activity $(i, j)$;

$N C_{i j[k]}$ the cost associated with the normal duration of the activity $(i, j)$;

$\widetilde{N C}_{i j[k]}$ the client's ambiguous perception of normal cost of activity $(i, j)$ of contractor $k\left(\widetilde{N C}_{i j}\right.$ is assumed a $L-R$ type fuzzy number $\left.\left(N C_{i j}, N C_{i j}^{-}, N C_{i j}^{+}\right)_{L_{N C_{i j}} R_{N C_{i j}^{+}}}\right)$;

$C C_{i j[k]}$ the cost associated with the crash duration of the activity $(i, j)$;

$\alpha_{i j[k]}$ the marginal cost of crashing activity $(i, j)$ with on time unit for contractor $k$, where $\alpha_{i j[k]}=\left(C C_{i j}-N C_{i j}\right) /\left(N D_{i j}-C D_{i j}\right), \forall(i, j) \in A_{[k]}$;

$\tilde{\alpha}_{i j[k]}$ the client's ambiguous perception of marginal cost of crashing activity $(i, j)$ of contractor $k$ ( $\tilde{\alpha}_{i j}$ is assumed a $L-R$ type fuzzy number $\left.\left(\alpha_{i j}, \alpha_{i j}^{-}, \alpha_{i j}^{+}\right)_{L_{\alpha_{i j}^{-}} R_{\alpha_{i j}^{+}}}\right)$;

$x_{i} \quad$ the realization (earliest) time of event (node) $i$;

$\Delta_{k} \quad$ the reservation profit of contractor $k$;

$F \quad$ the maximum threshold of project duration;

$G \quad$ the minimum threshold of project profit;

The following assumptions are made to specify the scope of this work for further model formulation:

1- There are some contractors and a client involved within a project and they are assumed to have rational behavior. That is, the client considers total profit and also total execution time of the project. However, the contractors are profit seeking companies.

2- The client sets a subset of project activities to be performed by each contractor. Each contractor decides about the execution time of each activity. All activities are compressible; i.e., the duration of each activity is a function of its assigned resources (money) and by spending more (or less) budget, the activity duration will reduce (rise). The time/cost function of each activity is assumed linear; i.e., by decreasing duration, the cost increases with a single slope. This assumption is commonly made in TCTPs (Moder et al., 1995; Vanhoucke, 2012).

3- Parameters are deterministic and known in advance.

4- The project client is a Stackelberg leader and the project contractors are Stackelberg followers. Thus, the interactions of the client and contractors conform a decentralized decision making 
schema where parties pursue their own goals. In decentralized decision-making structure, we assume the following time order of the members' game:

Stage 1: Project client determines the payments for each activity;

Stage 2: Project contractors jointly determine duration times of their activities.

The hierarchical game between leader and respective followers can be analysed by employing bi-level programming problem.

\section{The model formulation}

We consider project management as a decentralized non-cooperative decision system in which one client and several contractors are involved. That is, the client and contractors may have their own decision variables and objective functions. As shown in Fig. 1, the set of all projects activities are conducted by the client and each contractor implements a specific subset of project activities. The project client determines (normal and reward) payments to the contractors and the contractors specify how to implement the corresponding activities by time/cost trade-off analysis.

In this decentralized decision making, the client is regarded as a leader due to its leadership role and project contractors are regarded as the followers of the client (see Fig. 1). We model this decentralized decision making problem by BLDPP. A BLDPP is a hieratical decision making problem in which one decision center at the top level first takes the decision and then several divisions or decision centers at the bottom level make corresponding decisions in response to top level's decision (Lee \& Shih, 2001). The lower level divisions (or followers) are assumed in-dependent and under control of the upper level (leader); however, the followers have complete authority to optimize their objectives with regard to the decision of leader and other followers (Liu, 1998).

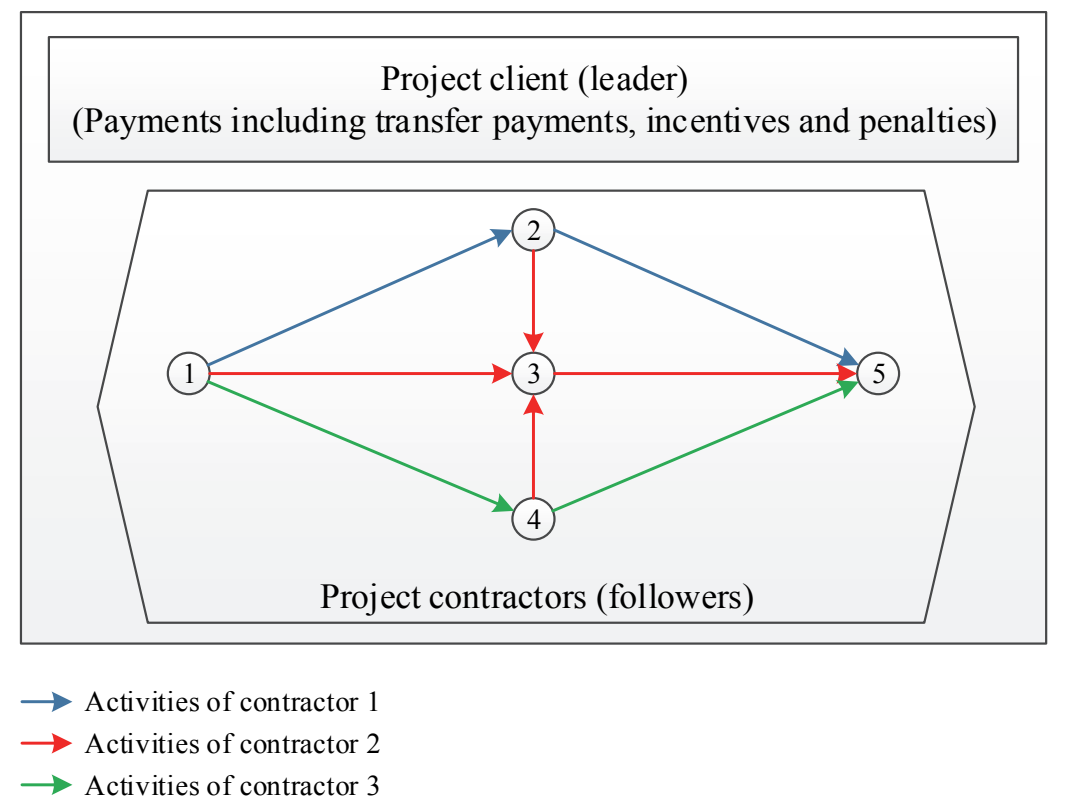

Fig. 1. AoA representation of project activities with multi-contractors and a client

Let $\boldsymbol{f}=\left\{f_{i j[k]} \mid f_{i j[k]} \geq 0, \forall(i, j) \in A_{[k]}, \forall k \in K\right\}$ and $\boldsymbol{e}=\left\{e_{i j[k]} \mid e_{i j[k]} \geq 0, \forall(i, j) \in A_{[k]}, \forall k \in K\right\}$ be sets of control decision variables of the client. Thus, the client determines payments (normal and reward payments) to the contractors to pursue specific policy of the project. The client may adopt three policies regarding profit seeking and minimization project duration behaviors as follows:

Policy 1: Profit seeking policy: 
$\max T P P(\boldsymbol{f}, \boldsymbol{e})$ subject to $T P D(\boldsymbol{f}, \boldsymbol{e})) \leq F$,

Policy 2: Minimization of project duration policy:

$\min \operatorname{TPD}(\boldsymbol{f}, \boldsymbol{e})$ subject to $\operatorname{TPP}(\boldsymbol{f}, \boldsymbol{e})) \geq G$,

Policy 3: Profit seeking and minimization of project duration policy:

$\max u(\boldsymbol{f}, \boldsymbol{e})=T P P(\boldsymbol{f}, \boldsymbol{e})-\theta \cdot T P D(\boldsymbol{f}, \boldsymbol{e})$.

In the profit seeking policy of the client, the total profit of project is maximized such that the total project duration do not exceed the threshold $F$. Many for-profit projects may be measured principally on financial benefits such as return on investment. In these kinds of projects, project duration may be only considered as a contractual limitation. The client with minimization of project duration policy aims to attenuate the duration of project considering pre-specific profit $G$. In some compulsory or notfor-profit projects, the projects should be implemented through the least time with specific budget (or profit). In the third policy, we assume that the client assesses its utility via project profit and duration where $\theta$ reflects the attitude of client towards minimization of the project duration.

Let $\boldsymbol{y}_{[k]}=\left\{y_{i j[k]} \mid y_{i j[k]} \geq 0, \forall(i, j) \in A_{[k]}\right\}$ and $\boldsymbol{x}=\left\{x_{i} \mid x_{i} \geq 0, \forall i \in E\right\}$ be the control decision variables of contractors. Thus, the client first chooses his control variables $\boldsymbol{f}$ and $\boldsymbol{e}$, and the contractors determine their control variables $\boldsymbol{y}$ and $\boldsymbol{x}$ after that. The client and contractors interaction can be formulated as follows:

$$
\max \operatorname{TPP}(\boldsymbol{f}, \boldsymbol{e})=\pi-\sum_{k \in K} \sum_{(i, j) \in A_{[k]}}\left(f_{i j[k]}+e_{i j[k]} y_{i j[k]}\right),
$$

$\min \operatorname{TPD}(\boldsymbol{f}, \boldsymbol{e})=x_{n}$,

subject to:

$$
\begin{aligned}
& \operatorname{Pos}\left\{\widetilde{T P}_{[k]}\left(\boldsymbol{y}_{[k]}, \boldsymbol{x}\right)=\sum_{(i, j) \in A_{[k]}}\left[\left(f_{i j[k]}-\widetilde{N C}_{i j[k]}\right)+\left(e_{i j[k]}-\tilde{\alpha}_{i j[k]}\right) y_{i j[k]}\right] \geq \widetilde{\Delta}_{k}\right\} \geq \beta, \forall k \in K, \\
& \operatorname{Pos}\left\{f_{i j[k]} \geq \widetilde{N C}_{i j[k]}\right\} \geq \gamma, \quad \forall(i, j) \in A_{[k]}, \forall k \in K, \\
& \operatorname{Pos}\left(e_{i j[k]} \geq \tilde{\alpha}_{i j[k]}\right) \geq \gamma, \quad \forall(i, j) \in A_{[k]}, \forall k \in K, \\
& \max T P_{[k]}\left(\boldsymbol{y}_{[k]}, \boldsymbol{x}\right)=\sum_{(i, j) \in A_{k k]}}\left[\left(f_{i j[\mathrm{k}]}-N C_{i j[k]}\right)+\left(e_{i j[k]}-\alpha_{i j[k]}\right) y_{i j[k]}\right], \\
& \text { subject to } \\
& N D_{i j}-y_{i j[k]} \geq C D_{i j}, \forall(i, j) \in A_{[k]} \text {, } \\
& x_{j} \geq x_{i}+N D_{i j}-y_{i j[k]}, \forall(i, j) \in A_{[k]} \text {, } \\
& y_{i j[k]} \geq 0, \forall(i, j) \in A_{[k]} \text {, } \\
& x_{j} \geq 0, \quad \forall j \in E \text {, } \\
& x_{1}=0 \text {, }
\end{aligned}
$$

where Pos represents the possibility. The client as a leader player maximizes his total project profit and total project duration in objective functions (4) and (5), respectively. Following the CPM convention let $x_{1}=0$, thus the time of the last event of the project, $x_{n}$, represents the project duration. Constraints (6)-(8) are fuzzy constraints that model the uncertain decision making space of the client. $\widetilde{T P}_{[k]}$ is 
client's ambiguous perception of total profit of contractor $k$. The client regards total profit of contractors to ensure their commitments. Inequality (6) is called Individual Rationality (IR) constraint under which a contractor of the project desires to perform corresponding project activities; otherwise, he will reject them and a specific part of the project will not implemented. Constraints (7)-(8) guarantee the satisfaction of contractors of performing each activity. Indeed, these constraints ensure that the normal and incentive payments of client for each activity are larger than normal cost and marginal crashing cost, respectively. Due to ambiguous perception of client about these costs, Constraints (6)-(8) are formulated as fuzzy constraints in which $\beta$ and $\gamma$ denote predetermined confidence levels of client about contractors' profits and their marginal costs, respectively.

Eqs. (9-14) represent TCTP for each contractor $k \in K$ (as follower). Thus, the best response strategy $\left(y_{[k]}^{*}, x^{*}\right)$ of the follower must be the optimal solution of the optimization problem Eqs. (9) - (14) (i.e., second level programming problem). Total project profit for the contractor $k$ is maximized in objective function (9). Constraint (10) limits the scheduled activity duration $(i, j)$ of contractor $k$, $N D_{i j}-y_{i j[k]}$, to be equal to or greater than the crash activity duration, $C D_{i j}$. Constraint (11) states that for activity $(i, j)$ of contractor $k$, the difference between the earliest node times, $x_{j}$ and $x_{i}$, must be at least as great as $N D_{i j}-y_{i j[k]}$, the scheduled duration of activity $(i, j)$.

The problem (4) - (14) is a bi-objective bi-level linear programming model. Adopting policies (1)-(3), this problem can be transformed into a single-objective bi-level, linear programming model. Generally, bi-level linear programming problem is classified as an NP-hard problem (Lee \& Shih, 2001; BenAyed \& Blair, 1990). The solution methods can be roughly classified into four categories of extremepoint search, transformation approaches, descent and heuristics and evolutionary approaches (Lee \& Shih, 2001 ). In transformation approach, the lower-level problems are transformed into constraints for the higher level by the use of different methods; e.g., the Karush-Kuhn-Tucker (KKT) conditions, and penalty functions.

\section{Solution approach}

Various solution methods have been proposed for BLDPP (Lee \& Shih, 2001). Anandalingam (1988) suggested a method for solving the BLDPP based on the KKT optimality conditions and the mixedinteger linear programming approach of Fortuny-Amat and McCarl (1981). Anandalingam and Apprey (1991) devised another method for solving the multiple agents system based on a penalty-function approach that was suggested for BLPP by Anandalingam and White (1991). Anandalingam and Apprey (1991) also studied the existence of Nash equilibrium under various situations and techniques for coordinating conflicting agents. Therefore, for our BLDPP between client and multiple contractors, we propose transformation approach based on Karush-Kuhn-Tucker (KKT) conditions developed by Fortuny-Amat and White (1990), Anandalingam (1988) and Anandalingam and White(1991).

The first step of solution procure is converting the fuzzy Constraints (6)-(8) into the crisp equivalents. For two fuzzy quantities $\tilde{a}$ and $\tilde{b}$, Zadeh (1999) showed that possibility of $\tilde{a} \leq \tilde{b}$ can be defined as follows:

$$
\operatorname{Pos}\{\tilde{a} \leq \tilde{b}\}=\sup \left\{\min \left(\mu_{\tilde{a}}(z) \leq \mu_{\tilde{b}}(v)\right) \mid z, v \in \mathbb{R}, z \leq v\right\},
$$

where $\mu_{a}$ and $\mu_{b}$ represent membership functions. For instance, possibility (15) for triangular fuzzy

numbers $\tilde{a}=\left(a_{1}, a_{2}, a_{2}\right)$ and $\tilde{b}=\left(b_{1}, b_{2}, b_{3}\right)$ can be formulated as follows: 


$$
\operatorname{Pos}\{\tilde{a} \leq \tilde{b}\}= \begin{cases}1, & \text { A. Hafezalkotob and A. Hafezalko } \\ \frac{b_{3}-a_{1}}{\left.b_{3}-b_{2}\right)+\left(a_{2}-a_{1}\right)}, & a_{2} \geq b_{2}, a_{1} \leq b_{3}, \\ 0, & a_{1} \geq b_{3} .\end{cases}
$$

Liu and Iwamura(1998) stated that possibility formulation (15) can be used for chance constrained programming with fuzzy parameters. Assume the following chance (fuzzy) constraint

$$
\operatorname{Pos}\{\xi \mid h(z) \leq \xi\} \geq \alpha
$$

where $\xi$ is a fuzzy variable and $h(z)$ is a function of decision vector $z$. Liu and Iwamura (1998) showed that the crisp equivalent of chance Constraint (17) is obtained as follows:

$$
h(\boldsymbol{z}) \leq \mu_{\xi}^{-1}(\alpha),
$$

in which $\mu_{\xi}^{-1}(\alpha)$ represents the inverse of the membership function $\mu_{\xi}$. According to Liu and Iwamura (1998), we use possibility (16) and Constraint (18) to formulate the crisp equivalents of fuzzy Constraints (6)-(8). Using the KKT optimality conditions, the transformation approach converts the lowerlevel problem into the constraints of the upper level. The transformed problem becomes one-level nonlinear programming problem; however, it is non-convex and complex. Therefore, various algorithms; e.g., penalty function, branch and bound, as well as mixed integer approach have been proposed for this problem (Lee and Shih, 2001). Among traditional optimization techniques, we select mixed integer approach developed by Fortuny-Amat and McCarl (1981). In the first step of transformation approach, we should substitute lower-level problem (7)-(12) for its KKT conditions. Therefore, the BLDPP (4)(14) can be transformed into the following first-level auxiliary problem:

$\max \operatorname{TPP}(\boldsymbol{f}, \boldsymbol{e})=\pi-\sum_{k \in K} \sum_{(i, j) \in A_{k k}}\left(f_{i j[k]}+e_{i j[k]} y_{i j[k]}\right)$,

$\min \operatorname{TPD}(\boldsymbol{f}, \boldsymbol{e})=x_{n}$,

subject to:

$$
\left.\begin{array}{ll}
\operatorname{Pos}\left(\sum_{(i, j) \in A_{[k]}}\left[\left(f_{i j[k]}-\widetilde{N C}_{i j[k]}\right)+\left(e_{i j[k]}-\widetilde{\alpha}_{i j[k]}\right) y_{i j[k]}\right] \geq \Delta_{k}\right) \geq \beta, \\
\operatorname{Pos}\left(f_{i j[k]} \geq \widetilde{N C}{ }_{i j[k]}\right) \geq \gamma, & \forall(i, j) \in A_{[k]}, \\
\operatorname{Pos}\left(e_{i j[k]} \geq \widetilde{\alpha}_{i j[k]}\right) \geq \gamma, & \forall(i, j) \in A_{[k]}, \\
\left(e_{i j[k]}-\alpha_{i j[k]}\right)-\lambda_{i j[k]}=0, & \forall(i, j) \in A_{[k]}, \\
\lambda_{i j[k]}\left(N D_{i j}-y_{i j[k]}-C D_{i j}\right)=0, & \forall(i, j) \in A_{[k]}, \\
N D_{i j}-y_{i j[k]}-C D_{i j} \geq 0, & \forall(i, j) \in A_{[k]}, \\
x_{j} \geq x_{i}+N D_{i j}-y_{i j[k]}, & \forall(i, j) \in A_{[k]}, \\
\lambda_{i j[k]} \geq 0, & \forall(i, j) \in A_{[k]}, \\
y_{i j[k]} \geq 0, & \forall(i, j) \in A_{[k]}, \\
x_{j} \geq 0, & \forall j \in E, \\
x_{1}=0 . &
\end{array}\right\} k k \in K
$$


Adopting the approach of Liu and Iwamura (1998), the crisp equivalents of fuzzy Constraints (21)-(23) are as follows:

$$
\begin{aligned}
& \frac{\left(\begin{array}{l}
\sum_{(i, j) \in A_{k]}}\left(f_{i j[k]}+e_{i j[k]} y_{i j[k]}\right)-\Delta_{k}-\sum_{(i, j) \in A_{k]}}\left(N C_{i j[k]}+\alpha_{i j[k]} y_{i j[k]}\right) \\
+\Delta_{k}^{-}+\sum_{(i, j) \in A_{k]}}\left(N C_{i j[k]}^{-}+\alpha_{i j[k]}^{-} y_{i j[k]}\right)
\end{array}\right)}{\sum_{(i, j) \in A_{k]}}\left(N C_{i j[k]}^{-}-\alpha_{i j[k]}^{-} y_{i j[k]}\right)} \geq \beta, \quad \forall k \in K \\
& \frac{f_{i j[k]}-\left(N C_{i j[k]}-N C_{i j[k]}^{-}\right)}{N C_{i j[k]}^{-}} \geq \gamma, \quad \forall(i, j) \in A_{[k]}, \forall k \in K, \\
& \frac{e_{i j[k]}-\left(\alpha_{i j[k]}-\alpha_{i j[k]}^{-}\right)}{\alpha_{i j[k]}^{-}} \geq \gamma, \quad \forall(i, j) \in A_{[k]}, \forall k \in K .
\end{aligned}
$$

Fuzzy Constraints (21)-(23), will be substituted for the Constraints (32)-(34) in the final model. On the other hand, we note that complementary slackness constraint (25) is nonlinear equation in the transformed problem. This condition states that one of the two terms, either $\lambda_{i j[k]}$ or $\left(N D_{i j}-y_{i j[k]}-C D_{i j}\right)$, must be equal to zero. Fortuny-Amat and McCarl (1981) proposed a reformulation for complementary slackness constraint by using mixed integer approach. Introducing $\eta_{i j[k]}$ as a zero-one decision variable, the complementary slackness constraint (21) can be substituted for the following either-or-constraints:

$$
\begin{array}{lrl}
N D_{i j}-y_{i j[k]}-C D_{i j} \leq \eta_{i j[k]} M, & \forall(i, j) \in A_{[k]}, \forall k \in K, \\
\lambda_{i j[k]} \leq\left(1-\eta_{i j[k]}\right) M, & \forall(i, j) \in A_{[k]}, \forall k \in K, \\
\eta_{i j[k]} \in\{0,1\}, & \forall(i, j) \in A_{[k]}, \forall k \in K,
\end{array}
$$

in which $M$ is a very large positive constant. Although the resulting formulation is a much larger programming problem, this formulation is very useful because several algorithms specialized in the context of mixed integer programming can be applied (Lee \& Shih, 2012). Using policies (1)-(3), the transformed problem becomes a mixed-integer (single objective) programming model and it can be solved by an ordinary operation research software e.g., Lingo or GAMS.

\section{Numerical example and discussion about the client decisions}

The large-scale projects; e.g., offshore or inshore constructions, high-tech or multidisciplinary projects and, construction of power generators plants are often implemented as EPC contracts. EPC is an acronym of engineering, procurement, and construction. Once the EPC contract is signed between the client and contractors, the client becomes committed to specific payments and contractors become liable for completing the project activities according to tender schedule. Regarding multiple decision making structures of EPC projects, managing time and cost of the project (e.g., TCTP) is extremely important for the client.

According to Fig. 1, we now evaluate interaction of a client with three contractors of EPC in which sets of activities $\{(1,2),(2,5)\},\{(1,3),(2,3),(4,3),(3,5)\}$, and $\{(1,4),(4,5)\}$ represent activities of engineering, procurement, and construction contractors, respectively. Tables 1 and 2 denote all network information for this example. This tables denotes the normal and crash time durations, the normal and crash costs of all activities, and minimum acceptable profit of contractors. 
Table 1

Input data for numerical example of EPC contractors

\begin{tabular}{|c|c|c|c|c|c|c|c|c|c|c|}
\hline & Activities & $N D_{i j}$ & $C D_{i j}$ & $N C_{i j}$ & $N C_{i j}^{-}$ & $N C_{i j}+$ & $C C_{i j}$ & $\alpha_{i j}$ & $\alpha_{i j}$ & $\alpha_{i j}{ }^{+}$ \\
\hline Contractor 1 & $(1,2)$ & 7 & 5 & 40 & 4 & 4 & 100 & 30 & 3 & 3 \\
\hline Engineering & $(2,5)$ & 6 & 5 & 120 & 12 & 12 & 180 & 60 & 6 & 6 \\
\hline Contractor 2 & $(1,4)$ & 8 & 5 & 200 & 20 & 20 & 290 & 30 & 3 & 3 \\
\hline Procurement & $(4,5)$ & 4 & 2 & 150 & 15 & 15 & 200 & 25 & 2.5 & 2.5 \\
\hline Contractor 3 & $(2,3)$ & 3 & 1 & 100 & 10 & 10 & 140 & 20 & 2 & 2 \\
\hline \multirow[t]{3}{*}{ Construction } & $(4,3)$ & 4 & 2 & 150 & 15 & 15 & 210 & 30 & 3 & 3 \\
\hline & $(1,3)$ & 9 & 4 & 200 & 20 & 20 & 400 & 40 & 4 & 4 \\
\hline & $(3,5)$ & 9 & 8 & 300 & 30 & 30 & 550 & 250 & 25 & 25 \\
\hline
\end{tabular}

Table 2

Expected profits of EPC contractors

\begin{tabular}{llll}
\hline & $\Delta$ & $\Delta^{-}$ & $\Delta^{+}$ \\
\hline Contractor 1 (E) & 90 & 9 & 9 \\
Contractor 2 (P) & 120 & 12 & 12 \\
Contractor 3 (C) & 100 & 10 & 10 \\
\hline
\end{tabular}

Tables 3-5 present the behavior of the model in scenarios 1-3, respectively. Table 3 illustrates how activities of contractors should be crashed in order to meet project deadline determined by the client. From the table, we also see how time of projects events depend on maximum project due date of the project. Table 4 shows the changes of expedition durations and activities times in the second scenario. From the table, we know that when the client expect low profit for himself, he enables the contractors to crash the durations of the activities to reduce total time of the project. In Table 5, we study the effect of the attitude of client towards minimization of project duration, $\theta$, in Scenario 3. As seen in the table, the coefficient $\theta$ has a diminishing effect on total profit of the client and total duration of the project.

Table 3

Sensitivity of the results in Scenario 1 to maximum project due date

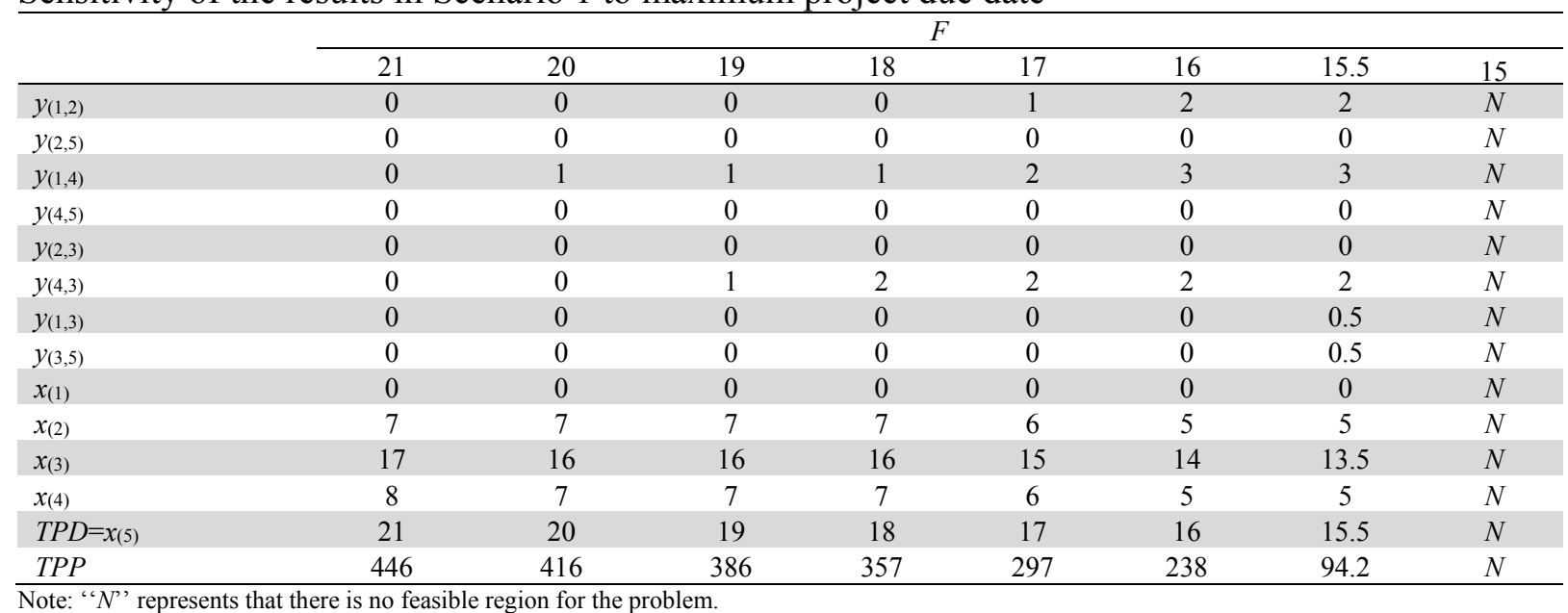

Overall, from Tables 4-5, we conclude that although the concepts of three scenarios (Eqs. 1-3) are different in project management, they result in similar relationships between profits of client and contractors. Moreover, three scenarios yield similar trade-offs between total time and cost of the project. This conclusion can be also drawn from the time/cost trade-off frontiers in Fig. 3. This figure shows that the higher the client profit, the higher the project duration in all scenarios will be. That is, when the client expects high profit from the project, he reduces the normal and incentive payments to contractors and then the contractors have poor motivation to expedite the project activities. 
Table 4

Sensitivity of the results in Scenario 2 to minimum project profit

\begin{tabular}{lllllll}
\hline & \multicolumn{7}{c}{$\mathrm{F}$} \\
\cline { 2 - 7 } & 100 & 200 & 300 & 400 & 430 & 500 \\
\hline$y_{(1,2)}$ & 2 & 2 & 0.95 & 0 & 0 & $N$ \\
$y_{(2,5)}$ & 0 & 0 & 0 & 0 & 0 & $N$ \\
$y_{(1,4)}$ & 3 & 3 & 1.95 & 1 & 0.53 & $N$ \\
$y_{(4,5)}$ & 0 & 0 & 0 & 0 & 0 & $N$ \\
$y_{(2,3)}$ & 0 & 0 & 0 & 0 & 0 & $N$ \\
$y_{(4,3)}$ & 2 & 2 & 2 & 0.54 & 0 & $N$ \\
$y_{(1,3)}$ & 0.48 & 0.13 & 0 & 0 & 0 & $N$ \\
$y_{(3,5)}$ & 0.48 & 0.13 & 0 & 0 & 0 & $N$ \\
$x_{(1)}$ & 0 & 0 & 0 & 0 & 0 & $N$ \\
$x_{(2)}$ & 5 & 5 & 6.05 & 7 & 7 & $N$ \\
$x_{(3)}$ & 13.5 & 13.9 & 15 & 16 & 16.5 & $N$ \\
$x_{(4)}$ & 5 & 5 & 6.05 & 7 & 7.47 & $N$ \\
\hline$T P D=x_{(5)}$ & 15.5 & 15.9 & 17 & 19.5 & 20.5 & $N$ \\
$T P P$ & 100 & 200 & 300 & 400 & 430 & $N$ \\
\hline Note: “ $N$ "' represents that there is no feasible region for the problem
\end{tabular}

Table 5

Sensitivity of the results in Scenario 3 to time minimization coefficient

\begin{tabular}{lllllll}
\hline & \multicolumn{7}{c}{$\theta$} & & & \\
\cline { 2 - 7 } & 0 & 1 & 10 & 50 & 100 & 1000 \\
\hline$y_{(1,2)}$ & 0 & 0 & 0 & 0 & 2 & 2 \\
$y_{(2,5)}$ & 0 & 0 & 0 & 0 & 0 & 0 \\
$y_{(1,4)}$ & 0 & 0 & 0 & 1 & 3 & 3 \\
$y_{(4,5)}$ & 0 & 0 & 0 & 0 & 0 & 0 \\
$y_{(2,3)}$ & 0 & 0 & 0 & 0 & 0 & 0 \\
$y_{(4,3)}$ & 0 & 0 & 0 & 2 & 2 & 2 \\
$y_{(1,3)}$ & 0 & 0 & 0 & 0 & 0 & 0.83 \\
$y_{(3,5)}$ & 0 & 0 & 0 & 0 & 0 & 0.83 \\
$x_{(1)}$ & 0 & 0 & 0 & 0 & 0 & 0 \\
$x_{(2)}$ & 7 & 7 & 7 & 7 & 5 & 5 \\
$x_{(3)}$ & 17 & 17 & 17 & 16 & 14 & 13.2 \\
$x_{(4)}$ & 8 & 8 & 8 & 7 & 5 & 5 \\
\hline$T P D=x_{(5)}$ & 21 & 21 & 21 & 18 & 16 & 15.2 \\
$T P P$ & 448 & 446 & 446 & 357 & 238 & 0 \\
\hline & & & & & & \\
\hline
\end{tabular}

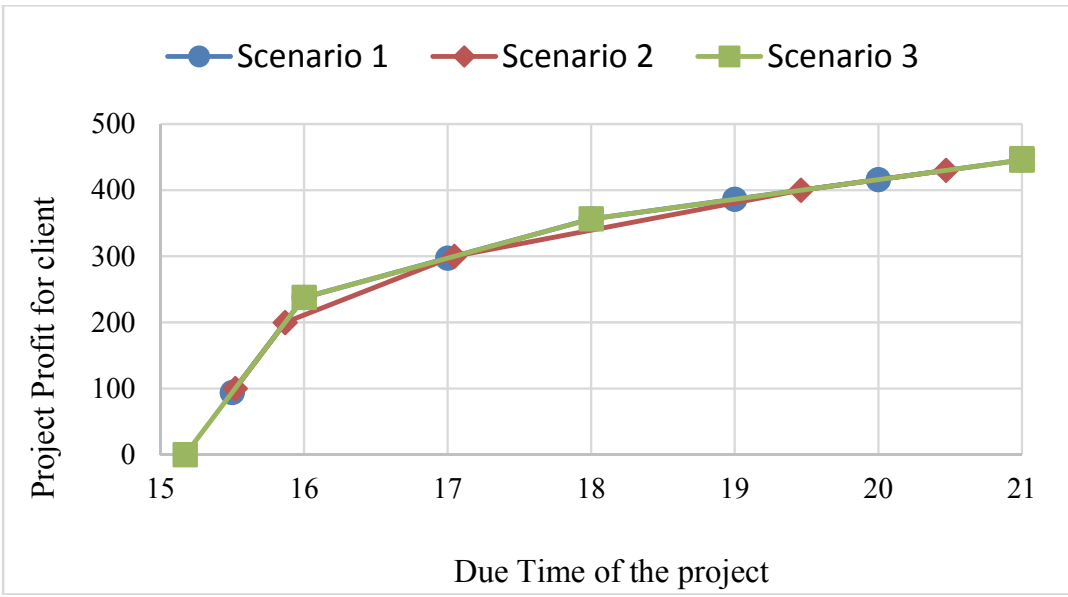

Fig. 3. Time/cost trade-offs of the project in three scenarios

Table 6 provides a sensitivity analysis of optimal payments and profits with respect to predetermined confidence levels of client about contractors' profits and their marginal cost (i.e. $\beta$ and $\gamma$ ). From the table, we find that when the client increases his confidence levels, the profits (and payments) obtained by contractors grow in three scenarios. On the other hand, high confidence levels decrease profit obtained by the clients. Therefore, when the client does not have complete information about his contractors' financial situations, he should consider trade-off between his confidence levels and his profit.

\section{Conclusion}

In this paper, we have considered the interaction of a client and multiple contractors under uncertain financial information of contractors. Each contractor manages and implements a subset of activities of a set of project activities. The client as high-level decision maker determines normal and incentive payments for activities to pursue profit seeking or/and minimization project duration policies considered in three scenarios. The time/cost trade-off between client and contractions is formulated as a fuzzy MOBLDPP. We propose transformation solution approach based on KKT conditions and mixed integer programming as a solution approach. 


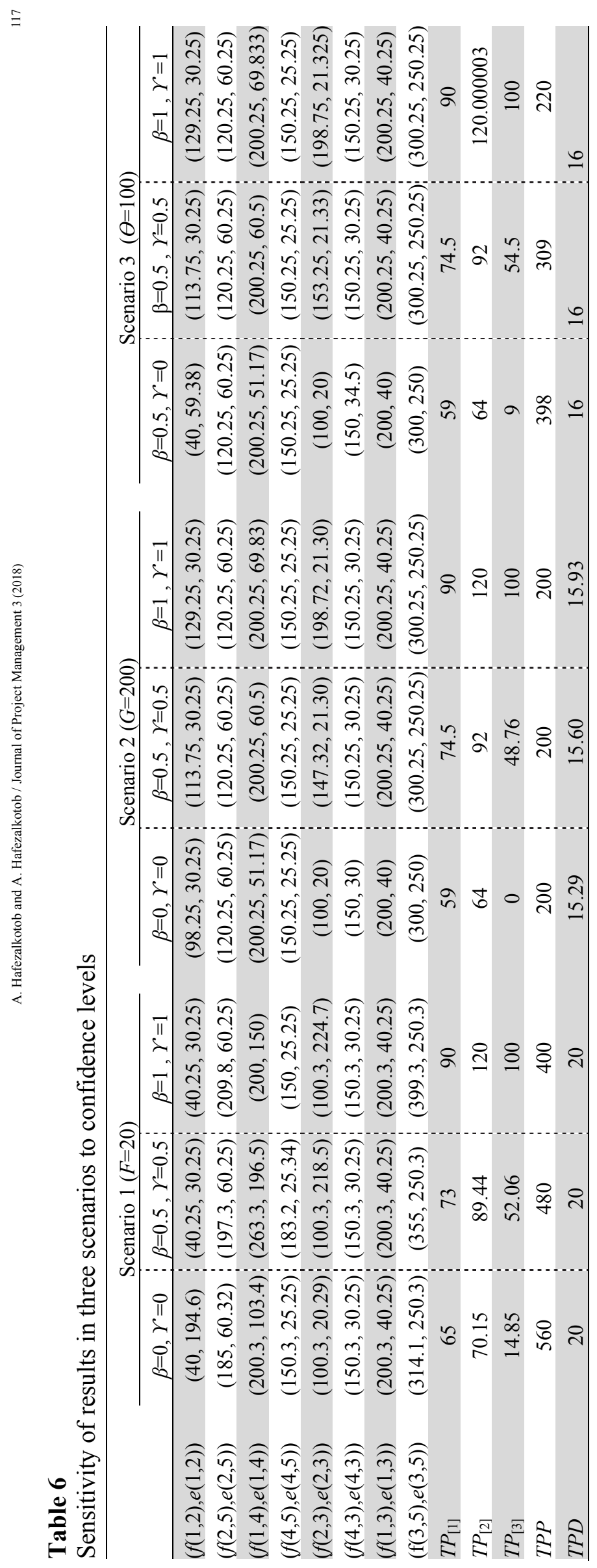


We have found that although the concepts of three scenarios of client's policy are different in project management, they yield similar results for all parties. The numerical example demonstrates that the client was able to shorten the project duration by raising the incentive payments to contractors for crashing the corresponding activities. Moreover, the sensitivity analyses reveal that analyzing the client's confidence levels and his profit is essential when the client does not complete information about contractors' financial situations.

Some directions for future researches can be suggested as follows. First of all, the uncertainty about durations of activities can also be considered. Secondly, we assume that the client is Stackelberg leader and contractors are Stackelberg followers. Nevertheless, the other decision-making structures are extremely appealing to be assessed in such model. Thirdly, incorporating the quality of implementation of activities by contractors into the TCTP is an interesting extension of our model.

\section{Acknowledgement}

The authors would like to thank the anonymous referees for constructive comments on earlier version of this paper.

\section{References}

Anandalingam, G. (1988). A mathematical programming model of decentralized multi-level systems. Journal of the Operational Research Society, 39(11), 1021-1033.

Anandalingam, G., \& Apprey, V. (1991). Multi-level programming and conflict resolution. European Journal of Operational Research, 51(2), 233-247.

Anandalingam, G., \& White, D. J. (1990). A solution method for the linear static Stackelberg problem using penalty functions. IEEE Transactions on Automatic Control, 35(10), 1170-1173.

Ben-Ayed, O., \& Blair, C. E. (1990). Computational difficulties of bilevel linear programming. Operations Research, 38(3), 556-560.

Berends, T. C. (2000). Cost plus incentive fee contracting - experiences and structuring. International Journal of Project Management, 18(3), 165-171.

Bubshait, A. A. (2003). Incentive/disincentive contracts and its effects on industrial projects. International Journal of Project Management, 21(1), 63-70.

Cheng, C. B. (2011). Reverse auction with buyer-supplier negotiation using bi-level distributed programming. European Journal of Operational Research,211(3), 601-611.

Fortuny-Amat, J., \& McCarl, B. (1981). A representation and economic interpretation of a two-level programming problem. Journal of the operational Research Society, 32(9), 783-792.

Ghoddousi, P., Eshtehardian, E., Jooybanpour, S., \& Javanmardi, A. (2013). Multi-mode resourceconstrained discrete time-cost-resource optimization in project scheduling using non-dominated sorting genetic algorithm.Automation in construction, 30, 216-227.

Hafezalkotob, A., Alavi, A., \& Makui, A. (2015). Government financial intervention in green and regular supply chains: Multi-level game theory approach. International Journal of Management Science and Engineering Management, 1-11.

Hafezalkotob, A., \& Ghezavati, V. R. (2015). Distribution network design of a decentralized supply chain with fuzzy committed distributors. Journal of Intelligent \& Fuzzy Systems, 29(2), 803-815.

Hafezalkotob, A., Hosseinpour, E., Moradi, M., \& Khalili-Damghani, K. (2017a). Multi-resource tradeoff problem of the project contractors in a cooperative environment: highway construction case study. International Journal of Management Science and Engineering Management, 1-10.

Hafezalkotob, A., Hoseinpour, E., \& Damghani, K. (2017b). A game theory approach for competition and cooperation among project's subcontractors with interaction activities. Journal of Project Management, 2(2), 71-86.

Hazır, Ö., Haouari, M., \& Erel, E. (2010). Discrete time/cost trade-off problem: A decomposition-based solution algorithm for the budget version.Computers \& Operations Research, 37(4), 649-655. 
Jian-hua, C., \& Wan, T. (2010, November). Time-cost trade-off problem in construction supply chain: A bi-level programming decision model. InManagement Science and Engineering (ICMSE), 2010 International Conference on (pp. 212-217). IEEE.

Kadefors, A. (2004). Trust in project relationships-inside the black box.International Journal of project management, 22(3), 175-182.

Kelley Jr, J. E., \& Walker, M. R. (1959, December). Critical-path planning and scheduling. In Papers presented at the December 1-3, 1959, eastern joint IRE-AIEE-ACM computer conference (pp. 160173). ACM.

Kelley Jr, J. E. (1961). Critical-path planning and scheduling: Mathematical basis. Operations research, 9(3), 296-320.

Klanšek, U., \& Pšunder, M. (2012). MINLP optimization model for the nonlinear discrete time-cost trade-off problem. Advances in Engineering Software, 48, 6-16.

Lee, E. S., \& Shih, H. S. (2012). Fuzzy and multi-level decision making: An interactive computational approach. Springer Science \& Business Media.

Liu, B. (1998). Stackelberg-Nash equilibrium for multilevel programming with multiple followers using genetic algorithms. Computers \& Mathematics with Applications, 36(7), 79-89.

Liu, B., \& Iwamura, K. (1998). Chance constrained programming with fuzzy parameters. Fuzzy sets and systems, 94(2), 227-237.

Lu, S., \& Hao, G. (2013). The influence of owner power in fostering contractor cooperation: Evidence from China. International Journal of Project Management, 31(4), 522-531.

Moder J. J., Phillips C. R. \& Davis E. W. (1995) Project Management With Cpm, Pert \& Precedence Diagramming . Blitz Publishing Company; 3rd edition.

Mokhlesian, M., \& Zegordi, S. H. (2014). Application of multidivisional bi-level programming to coordinate pricing and inventory decisions in a multiproduct competitive supply chain. The International Journal of Advanced Manufacturing Technology, 71(9-12), 1975-1989.

Rahman, M. M., \& Kumaraswamy, M. M. (2002). Joint risk management through transactionally efficient relational contracting. Construction Management \& Economics, 20(1), 45-54.

Son, J., Hong, T., \& Lee, S. (2013). A mixed (continuous+ discrete) time-cost trade-off model considering four different relationships with lag time.KSCE Journal of Civil Engineering, 17(2), 281291.

Suprapto, M., Bakker, H. L., Mooi, H. G., \& Moree, W. (2015). Sorting out the essence of ownercontractor collaboration in capital project delivery.International Journal of Project Management, 33(3), 664-683.

Vaaland, T. I. (2004). Improving project collaboration: start with the conflicts.International Journal of Project Management, 22(6), 447-454.

Vanhoucke, M. (2012). Project management with dynamic scheduling. Springer Berlin Heidelberg.

Von Branconi, C., \& Loch, C. H. (2004). Contracting for major projects: eight business levers for top management. International Journal of Project Management, 22(2), 119-130.

Wu, C., Wang, X., \& Lin, J. (2014). Optimizations in project scheduling: a state-of-art survey. In $O p$ timization and control methods in industrial engineering and construction (pp. 161-177). Springer Netherlands.

Xiong, B., Skitmore, M., Xia, B., Masrom, M. A., Ye, K., \& Bridge, A. (2014). Examining the influence of participant performance factors on contractor satisfaction: A structural equation model. International Journal of Project Management, 32(3), 482-491.

Yang, K., Zhao, R., \& Lan, Y. (2016). Incentive contract design in project management with serial tasks and uncertain completion times. Engineering Optimization, 48(4), 629-651.

Yin, S., Nishi, T., \& Grossmann, I. E. (2015). Optimal quantity discount coordination for supply chain optimization with one manufacturer and multiple suppliers under demand uncertainty. The International Journal of Advanced Manufacturing Technology, 76(5-8), 1173-1184.

Zadeh, L. A. (1999). Fuzzy sets as a basis for a theory of possibility. Fuzzy sets and systems, 100, 934. 


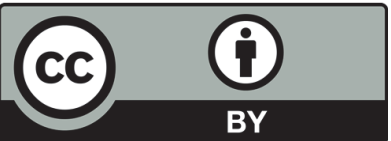

(C) 2018 by the authors; licensee Growing Science, Canada. This is an open access article distributed under the terms and conditions of the Creative Commons Attribution (CC-BY) license (http://creativecommons.org/licenses/by/4.0/). 